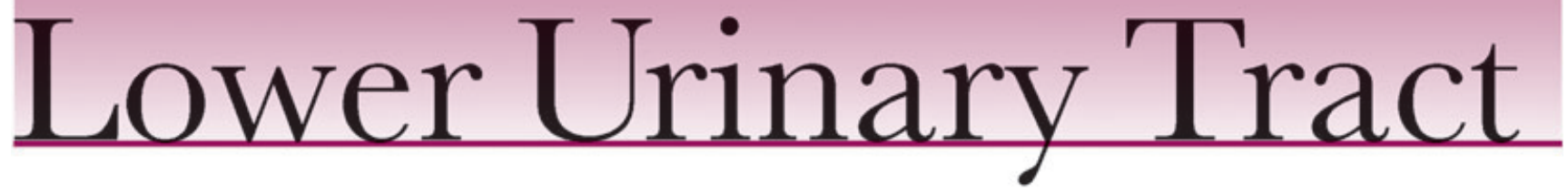

\title{
Correlation of the International Prostate Symptom Score bother question with the Benign Prostatic Hyperplasia Impact Index in a clinical practice setting
}

\author{
Michael P. O'Leary, John T. Wei*, Claus G. Roehrbornt and Martin Minerキ for the BPH \\ Registry and Patient Survey Steering Committee \\ Harvard Medical School, Brigham and Women's Hospital, Boston, MA, *The University of Michigan, Ann Arbor, MI, tThe \\ University of Texas Southwestern Medical Center, Dallas, TX, and $\neq$ Warren Alpert School of Medicine of Brown University, \\ Providence, RI, USA
}

Accepted for publication 21 November 2007

\section{Study Type - Symptom prevalence study (inception cohort) \\ Level of Evidence $2 a$}

\section{OBJECTIVE}

To evaluate the association between the International Prostate Symptom Score (IPSS) bother question (BO) and a validated diseasespecific quality-of-life questionnaire, the Benign Prostatic Hyperplasia (BPH) Impact Index (BPH-II), using the BPH Registry and Patient Survey database.

\section{PATIENTS AND METHODS}

The BPH Registry and Patient Survey is a multicentre, longitudinal, observational database of management practices and patient outcomes in a population of patients with BPH in the USA, managed with watchful waiting or pharmacotherapy. Men enrolled in the BPH Registry who completed the IPSS BO and the four-item BPH-II at enrolment were identified. The association between the IPSS BO score and the BPH Impact Index was assessed using Spearman rank correlation.

\section{RESULTS}

At baseline (enrolment visit), 6439 men (mean age 66 years) completed the IPSS BO and the $\mathrm{BPH}-\mathrm{II}$. The mean (SD) score of the IPSS BO was 2.5 (1.4) and of the BPH-II was 2.8 (2.8). Based on responses to the $\mathrm{BPH}-\mathrm{II}$, at least half the men reported that their urinary symptoms were associated with physical discomfort, worry about their health, and bothersomeness. The IPSS BO score was significantly correlated $(P<0.001)$ with the BPH-II $(r=0.68)$ and each of its four questions (physical discomfort, $r=0.52$; worry about health, $r=0.53$; bothersomeness of trouble with urination, $r=0.67$; and time kept from usual activities, $r=0.44$ ).

\section{CONCLUSIONS}

The IPSS BO score has a strong and positive correlation with the $\mathrm{BPH}-\mathrm{Il}$ among men enrolled in the BPH Registry. The IPSS BO is a convenient tool for assessing disease-specific quality of life when determining treatment strategies and evaluating treatment outcomes in men with BPH.

\section{KEYWORDS}

benign prostatic hyperplasia, lower urinary tract symptoms, bother score, disease-specific quality of life

\section{INTRODUCTION}

$\mathrm{BPH}$ is a common health problem in ageing men, affecting $50-80 \%$ of men aged 50 80 years [1]. Many men with BPH develop moderate-to-severe LUTS, including a weak urinary stream, hesitancy during urination, straining to initiate urination, increased frequency of urination, nocturia, and a sensation of incomplete bladder emptying after urination, that can be bothersome and compromise their quality of life $(\mathrm{QoL})[2,3]$. The bother associated with LUTS/BPH is the main reason that men seek treatment, and a key decision point in the diagnosis and treatment algorithm of the AUA 2003 guidelines on managing BPH [4]. In general, watchful waiting is the standard recommendation for men with $\mathrm{BPH}$ and mild or moderate-to-severe LUTS that are not bothersome, whereas watchful waiting, 
medical therapy, e.g. $\alpha_{1}$-adrenergic blockers (ABs), $5 \alpha$-reductase inhibitors (5ARIs), and $A B$ plus $5 A R I$ combined, minimally invasive therapy, or surgical therapy are recommended management options for men with bothersome moderate-to-severe LUTS associated with BPH [4].

The seven-item AUA Symptom Index, developed and psychometrically validated by an AUA Measurement Committee in 1992, reliably assesses the severity of LUTS and is responsive to changes in treatment [5]. The eight-item IPSS, which uses the same seven questions assessing LUTS severity as the AUA Symptom Index, plus an eighth diseasespecific QoL question that assesses the bother associated with LUTS, was adopted by the WHO in 1993 [6]. The IPSS bother question (BO) is the most commonly used measure of $\mathrm{QoL}$ in the evaluation of men with BPH [7]. Various studies have shown the reliability, validity and sensitivity of the IPSS BO $[5,8,9]$ and the strong positive association between LUTS severity and the IPSS BO score for men from different countries and cultural backgrounds [2,9-14]. Thus, it has been suggested that the IPSS BO is a simple and reliable tool for assessing treatment outcomes in men with bothersome LUTS/BPH [15]. To further test this hypothesis, we evaluated the association between the IPSS $\mathrm{BO}$ and a validated disease-specific $\mathrm{OoL}$ instrument, the BPH Impact Index (BPH-II) [8], using baseline data from the BPH Registry and Patient Survey.

\section{PATIENTS AND METHODS}

The BPH Registry and Patient Survey is a prospective, multicentre, longitudinal, observational disease registry designed to examine patient characteristics and outcomes and physician management practices in men with LUTS/BPH in the USA who are managed with watchful waiting or pharmacotherapy by urologists or primary-care providers. The registry, which was sponsored by SanofiAventis, was designed and developed by a 20-member Steering Committee composed of urologists, primary-care physicians, psychologists and a biostatistician. A full description of the design of the registry was published previously [16]. In brief, men with LUTS/BPH were eligible for enrolment if they provided consent and were: presently/ recently treated with approved prescription medications for the symptoms of BPH,

$\begin{array}{lcl}\text { Variable }(n) & \text { Value } & \text { TABLE 1 } \\ \text { Mean (SD) age, years (6382) } & 66.0(10.3) & \begin{array}{l}\text { The patients' characteristics } \\ \text { at baseline }\end{array} \\ \text { Race, } n \text { (\%) (6366) } & 5302(83) & \\ \text { White/Caucasian } & 603(9) & \\ \text { Black/African American } & 461(7) & \\ \text { Other } & 3.0 & \\ \text { Median years since BPH diagnosis (5555) } & 3028(47) \\ \text { BPH management before enrolment, } n(\%)(6439) & 2020(31) \\ \text { No treatment } & 400(6) \\ \text { AB monotherapy } & 670(10) \\ 5 \text { ARI monotherapy } & 123(2) \\ \text { AB + 5ARI } & 198(3) \\ \text { Anticholinergics (monotherapy or combined } & \\ \quad \text { therapy) } & 802(17) \\ \text { Other or missing data } & 2095(43) \\ \text { Prostate volume on DRE, } n \text { (\%) (4821) } & 1612(33) \\ \text { Normal } & 312(6) \\ \text { Slightly enlarged } & 1.8 \\ \text { Moderately enlarged } & \\ \text { Significantly enlarged } & \\ \text { Median total PSA level, ng/mL (4919) } & \end{array}$

untreated (i.e. managed with watchful waiting or newly diagnosed), or currently taking botanical products. Exclusion criteria included lower urinary tract disease or carcinoma, carcinoma of the prostate, bladder or kidney, previous prostate surgery or minimally invasive procedure, isolated bladder neck disease or urethral stenosis/strictures, gross haematuria, acute urinary retention, neurological disease affecting urinary function, active kidney or liver disease, and use of LHRH analogues or antiandrogens.

At the baseline visit, men completed a demographic questionnaire and various other questionnaires, including the IPSS BO [5] and the four-item BPH-II [8]. The IPSS BO ('If you were to spend the rest of your life with your urinary condition just the way it is now, how would you feel about that?') had scores of 0 (delighted), 1 (pleased), 2 (mostly satisfied), 3 (mixed about equally satisfied and dissatisfied), 5 (mostly dissatisfied), 5 (unhappy), and 6 (terrible), with higher scores indicating worse $\mathrm{CoL}$. The four questions of the BPH-II are: (i) Over the past month, how much physical discomfort did any urinary problem cause you?; (ii) Over the past month, how much did you worry about your health because of any urinary problems?; (iii) Overall, how bothersome has any trouble with urination been during the past month?; and (iv) Over the past month, how much time has any urinary problem kept you from the kinds of things you would usually do? For the BPH
Registry, each question of the BPH-II had scores of 0 (none/not at all), 1 (only a little/ bothers me a little), 2 (some/bothers me some), and 3 (a lot/all of the time), with the total score calculated as the sum of the scores of the individual questions. Therefore, for the BPH Registry, the total score of the BPH-II was $0-12$, with a higher score indicating worse OoL. Investigators collected information on disease history, clinical history, relevant concomitant medications, laboratory data, vital signs, and common complaints associated with BPH treatment.

Men enrolled in the BPH Registry who completed the IPSS BO and the BPH-II at the baseline visit were identified. The association between the IPSS BO and the BPH-II was assessed using Spearman rank correlation.

\section{RESULTS}

Of 6909 patients enrolled in the BPH Registry by urologists (4537 patients) and primarycare physicians (2372 patients) at 402 sites in the USA, 6439 (93\%) completed both the IPSS $\mathrm{BO}$ and the BPH-II at baseline (enrolment visit). The baseline demographics and clinical characteristics of these 6439 patients (Table 1) were comparable with those of the entire cohort of enrolled men. The median (range) age of the 6439 men was 67 (30-90) years, with 3028 (47\%) not treated for their BPH before enrolment in the BPH 
FIG. 1.

Responses to the BPH-II questions; higher scores indicate a greater negative impact of urinary symptoms; percentages might not total $100 \%$ due to rounding.

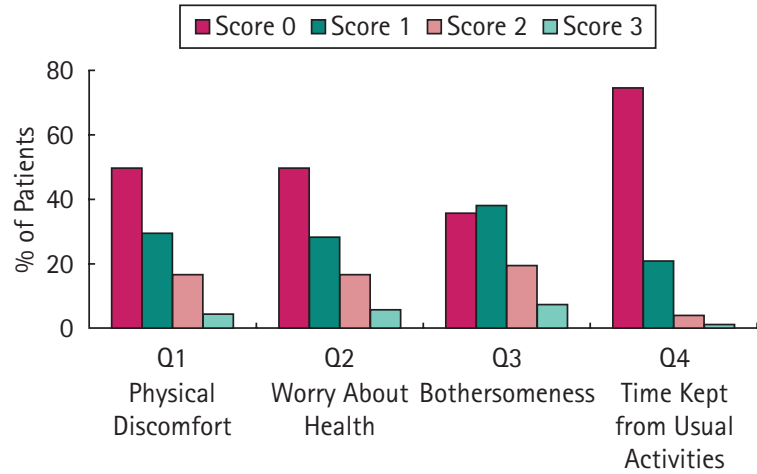

\begin{tabular}{|c|c|c|}
\hline Question & Mean (SD) score & TABLE 2 \\
\hline IPSS BO score (range $0-6^{*}$ ) & $2.5(1.4)$ & The QoL scores at baseline \\
\hline $\mathrm{BPH}-\mathrm{II}$ & & for the 6439 men \\
\hline Q1: Physical discomfort (score $0-3+$ ) & $0.8(0.9)$ & \\
\hline 02: Worry about health (score $0-3+$ ) & $0.8(0.9)$ & \\
\hline Q3: Bothersomeness (score 0-3t) & $1.0(0.9)$ & ${ }^{*}$ Higher score indicates \\
\hline Q4: Time kept from usual activities (score $0-3+$ ) & $0.3(0.6)$ & greater bother. tHigher \\
\hline Total $(0-12+)$ & $2.8(2.8)$ & score indicates worse QoL. \\
\hline
\end{tabular}

\begin{tabular}{|c|c|c|c|}
\hline IPSS BO Score correlation with: & $\begin{array}{l}\text { Correlation } \\
\text { coefficient, } r\end{array}$ & $P$ & \multirow{7}{*}{$\begin{array}{l}\text { TABLE } 3 \\
\text { Correlation between the } \\
\text { IPSS BO score and BPH-II }\end{array}$} \\
\hline$\overline{\mathrm{BPH}-\mathrm{II}}$ & & & \\
\hline Q1: Physical discomfort & 0.52 & $<0.001$ & \\
\hline Q2: Worry about health & 0.53 & $<0.001$ & \\
\hline Q3: Bothersomeness & 0.67 & $<0.001$ & \\
\hline Q4: Kept from usual activities & 0.44 & $<0.001$ & \\
\hline Total & 0.68 & $<0.001$ & \\
\hline
\end{tabular}

Registry and 3213 (50\%) treated with $A B$ monotherapy, 5ARI monotherapy, $A B+5 A R I$ combined therapy, or anticholinergics before enrolment. The remaining 198 (3\%) men were treated with other medications or their BPH management data were not available.

The mean (SD) scores of the IPSS BO and the $\mathrm{BPH}-\mathrm{Il}$ at baseline are listed in Table 2. Based on responses to the four questions of the $\mathrm{BPH}-\mathrm{II}$, most of the 6439 men with $\mathrm{BPH}$ reported that during the past month their urinary problems were associated with physical discomfort (3206, 50\%), worry about their health $(3194,50 \%)$, and bothersomeness (4104, 64\%) (Fig. 1). Only 1610 (26\%) of the 6439 men reported that any urinary problem kept them from doing their usual activities. The IPSS BO score was significantly $(P<0.001)$ and positively correlated with the total score and the score for each of the four questions of the BPH-II (Table 3). The strongest correlations were between the IPSS $\mathrm{BO}$ and question 3 (bothersomeness of trouble with urination, $r=0.67)$ and the total score of the BPH-II ( $r=0.68$, Table 3$)$.

\section{DISCUSSION}

In men with LUTS/BPH who were enrolled in the BPH Registry, the IPSS BO has a significant and strong positive correlation with the $\mathrm{BPH}$ II [8], a validated disease-specific measure of OoL that is used as a measure of treatment outcomes in men with symptomatic BPH. The present results confirm a previous report of a strong positive association between the IPSS BO score and the BPH-II $(r=0.62)$ in 4800 men, aged $40-79$ years, surveyed in the UrEpik study [17], and further support the hypothesis that the IPSS BO is a simple and valid measure that can be useful for assessing treatment outcomes in men with symptomatic BPH [15]. Preliminary data from the BPH Registry database indicated that the IPSS BO score was only weakly correlated with the Short Form-12, a generic QoL questionnaire. Using baseline data from 589 men enrolled during the first 3 months of the BPH Registry, the Pearson product-moment correlation coefficients for the IPSS BO score with the Short Form-12 physical component summary score and the mental component summary score were -0.12 and -0.18 , respectively [18]. These data suggested that the generic Short Form-12 might not adequately measure the bother associated with LUTS/BPH, confirming previous reports $[7,19,20]$.

The bothersomeness and impact of LUTS on $\mathrm{QoL}$ is the main reason why men seek treatment for BPH $[4,21,22]$. The current AUA guideline on the management of $\mathrm{BPH}$, issued in 2003, states that the impact of LUTS/BPH on a patient's OoL, especially the bothersomeness of LUTS, should be the primary consideration in treatment decisions and in assessments of treatment response and disease progression [4]. Although various validated QoL instruments have been used to assess disease-specific QoL in men with LUTS/BPH, the IPSS BO is the easiest to administer and the most widely accepted and used [7]. The IPSS BO score has been used extensively to assess disease-specific QoL in placebo-controlled clinical trials evaluating pharmacotherapy for treating $\mathrm{BPH}$. In the single-arm weighted average of all studies evaluating $A B s, 5 A R I s$, combined therapy, or controls conducted by the AUA and used as a basis for the 2003 guideline, the IPSS BO score improved (decreased) from baseline twice as much with $A B s$ as with placebo, twice as much with combined therapy as with placebo, and the same with 5ARIs as with placebo in studies of 3-9 months' duration [23]. These results suggest that $A B s$ improve $\mathrm{CoL}$ more than 5ARIs, with $A B$ plus 5ARI therapy providing no further improvement than $A B$ monotherapy. Although the BPH-II was used to assess QoL in fewer studies of 3-9 months' duration than the IPSS BO in the AUA single-arm weighted analysis, the overall trends in improvements in QoL for different pharmacotherapies, as assessed with the BPH-II, were comparable with those assessed with the IPSS BO [23]. Diseasespecific QoL measures, e.g. the IPSS BO score, have been shown to improve to a greater extent in response to $\mathrm{BPH}$ treatment than generic measures of $\mathrm{QoL}$ [7]. Thus, the IPSS BO 
score, which is responsive to clinical changes, can be useful in evaluating the efficacy of treatments for $\mathrm{BPH}$.

In addition to the present results, various studies documented the validity of the IPSS BO. In the formal validation of the AUA Symptom Index (subsequently adopted as the IPSS), two overall BOs were evaluated for their correlation with the symptom severity questions and with each other [5]. The overall $\mathrm{BO}$ that is now known as the IPSS BO correlated strongly $(r=0.71)$ with the sevenitem AUA Symptom Index and with the other overall BO ( $r=0.82)$ [5], showing construct validity and internal reliability, respectively. The Multinational Survey of the Aging Male, which examined the relationship between LUTS and sexual dysfunction in ageing men, confirmed the significant association between LUTS severity and LUTS bother, as assessed with the IPSS BO [9]. Other studies also confirmed this significant association between LUTS severity and the IPSS BO score $[10,24-27]$ and between the IPSS BO score and other measures of LUTS bother $[17,24]$. A recent study of a visual analogue scale version of the IPSS and IPSS BO reported a significant test-retest reliability of the original IPSS BO score in both healthy men $(r=0.91)$ and men with LUTS $(r=0.67)$ [26]. Because the IPSS B0 score is directly related to LUTS severity and is highly correlated with other disease-specific OoL measures, the IPSS BO score represents a valuable tool for assessing treatment outcomes in men with LUTS/BPH. Just as the assessment of LUTS severity in men with $\mathrm{BPH}$ was standardized with the IPSS, standardization of the assessment of diseasespecific OoL with the IPSS BO will facilitate comparisons of QoL endpoints across different studies.

In conclusion, among men enrolled in the BPH Registry, the IPSS BO, a disease-specific $\mathrm{OoL}$ measure, had a strong positive correlation with the total BPH-II and each of its four questions. These results further support the validity of the IPSS BO as a convenient tool for assessing disease-specific QoL that can be used in conjunction with the IPSS when determining treatment strategies and evaluating treatment outcomes in men with LUTS/BPH.

\section{ACKNOWLEDGEMENTS}

The members of the BPH Registry and Patient Survey Steering Committee are: Stanley E.
Althof, Cleveland, Ohio; Steven Kaplan, New York, NY; Mark S. Litwin, Los Angeles, California; Michael Manyak, Washington, DC; Leonard S. Marks, Los Angeles, California; Kevin T. McVary, Chicago, Illinois; Charles Metzger, Glendora, California; Martin Miner, Swansea, Massachusetts; James Nuckolls, Roanoke, Virginia; Michael P. O'Leary, Boston, Massachusetts; David Pasta, San Francisco, California; Richard Payne, Encinitas, California; David Penson, Los Angeles, California; Michael Perelman, New York, NY; Claus G. Roehrborn, Dallas, Texas; Raymond C. Rosen, Watertown, Massachusetts; Allen D. Seftel, Cleveland, Ohio; William Steers, Charlottesville, Virginia; Alexis E. Te, New York, NY; John T. Wei, Ann Arbor, Michigan. The BPH Registry and Patient Survey is supported by sanofi-aventis, and all members of the BPH Registry and Patient Survey Steering Committee were paid consultants. Martin Miner, James Nuckolls, Richard Payne, William Steers, and John Wei also served as site investigators for the $\mathrm{BPH}$ Registry and Patient Survey. Patricia B. Leinen, $\mathrm{PhD}$, contributed to the preparation of the manuscript.

\section{CONFLICT OF INTEREST}

Michael P. O'Leary is a Study Investigator funded by the Sponsor. John T. Wei and Claus G. Roehrborn are Paid Consultants to the Sponsor. Martin Miner is a Paid Consultant to the Sponsor and GSK. Source of Funding: Sanofi-Aventis, AMS, Envisioneering.

\section{REFERENCES}

1 Berry SJ, Coffey DS, Walsh PC, Ewing LL. The development of human benign prostatic hyperplasia with age. $J$ Urol 1984; 132: 474-9

2 Girman CJ, Epstein RS, Jacobsen SJ et al. Natural history of prostatism: impact of urinary symptoms on quality of life in 2115 randomly selected community men. Urology 1994; 44: 825-31

3 O'Leary MP. LUTS, ED and QOL: alphabet soup or real concerns to aging men? Urology 2000; 56: 7-11

4 AUA Practice Guidelines Committee. AUA guideline on management of benign prostatic hyperplasia (2003). Chapter 1: diagnosis and treatment recommendations. J Uro/ 2003; 170: 53047
5 Barry MJ, Fowler FJ Jr, O'Leary MP et al. The American Urological Association symptom index for benign prostatic hyperplasia. The Measurement Committee of the American Urological Association. J Urol 1992; 148: 1549-57

6 Cockett ATK, Khoury S, Aso Y et al. eds. The 2nd International Consultation on $B P H$, Proceedings. Jersey, Channel Islands: Scientific Communication International, Ltd, 1993

7 Batista-Miranda JE, Diez MD, Bertran PA, Villavicencio H. Quality-of-life assessment in patients with benign prostatic hyperplasia: effects of various interventions. Pharmacoeconomics 2001; 19: 1079-90

8 Barry MJ, Fowler FJ Jr, O'Leary MP, Bruskewitz RC, Holtgrewe HL, Mebust WK. Measuring disease-specific health status in men with benign prostatic hyperplasia. Measurement Committee of the American Urological Association. Medical Care 1995; 33: AS145-55

9 Rosen R, Altwein J, Boyle P et al. Lower urinary tract symptoms and male sexual dysfunction: the multinational survey of the aging male (MSAM-7). Eur Uro/ 2003; 44: 637-49

10 Flanigan RC, Reda DJ, Wasson JH, Anderson RJ, Abdellatif M, Bruskewitz RC. 5-year outcome of surgical resection and watchful waiting for men with moderately symptomatic benign prostatic hyperplasia: a Department of Veterans Affairs cooperative study. J Urol 1998; 160: 12-6

11 Yoshimura K, Arai Y, Ichioka K, Terada N, Matsuta Y, Okubo K. Symptomspecific quality of life in patients with benign prostatic hyperplasia. Int J Urol 2002; 9: 485-90

12 Roehrborn CG, Van Kerrebroeck P, Nordling J. Safety and efficacy of alfuzosin $10 \mathrm{mg}$ once-daily in the treatment of lower urinary tract symptoms and clinical benign prostatic hyperplasia: a pooled analysis of three double-blind, placebo-controlled studies. BJU Int 2003; 92: 257-61

13 Ganpule AP, Desai MR, Desai MM, Wani KD, Bapat SD. Natural history of lower urinary tract symptoms: preliminary report from a communitybased Indian study. BJU Int 2004; 94 : 332-4

14 Andersson SO, Rashidkhani B, Karlberg $\mathrm{L}$, Wolk $A$, Johansson JE. Prevalence of lower urinary tract symptoms in men 
aged 45-79 years: a population-based study of 40000 Swedish men. BJU Int 2004; 94: 327-31

15 O'Leary MP. Validity of the 'bother score' in the evaluation and treatment of symptomatic benign prostatic hyperplasia. Rev Urol 2005; 7: 1-10

16 Roehrborn CG, Nuckolls JG, Wei JT, Steers W. The BPH Registry and Patient Survey: study design, methods, and patient baseline characteristics. $B J U$ Int 2007; 100: 813-9

17 Boyle P, Robertson C, Mazzetta C et al. The relationship between lower urinary tract symptoms and health status: the UREPIK study. BJU Int 2003; 92: 575-80

18 O'Leary M, Litwin M, Manyak M, Miner M, Penson D, Roehrborn C. Correlation of International Prostate Symptom Score bother question with the Benign Prostatic Hyperplasia Impact Index and SF-12 in a practice setting. J Urol 2005; 173 (4 Suppl.): Abstract \#4

19 Rhodes PR, Krogh RH, Bruskewitz RC. Impact of drug therapy on benign prostatic hyperplasia-specific quality of life. Urology 1999; 53: 1090-8

20 Donovan JL, Kay HE, Peters TJ et al. Using the ICSOoL to measure the impact of lower urinary tract symptoms on quality of life: evidence from the ICS'BPH' Study. International Continence Society - Benign Prostatic Hyperplasia. Br J Urol 1997; 80: 712-21

21 Berges RR, Pientka L, Hofner K, Senge $T$, Jonas $U$. Male lower urinary tract symptoms and related health care seeking in Germany. Eur Urol 2001; 39: 682-7

22 Jacobsen SJ, Girman CJ, Guess HA et al. Natural history of prostatism: factors associated with discordance between frequency and bother of urinary symptoms. Urology 1993 2003; 42: 66371

23 AUA Practice Guidelines Committee. AUA Guideline on Management of Benign Prostatic Hyperplasia. Chapter 3: results of the treatment outcomes analyses. American Urological Association. Available at: http://www.AUAnet.org. Accessed 27 October 2007

24 Sagnier PP, MacFarlane G, Teillac P, Botto H, Richard F, Boyle P. Impact of symptoms of prostatism on level of bother and quality of life of men in the French community. J Urol 1995; 153: 669-73

25 Stroberg P, Boman H, Gellerstedt M, Hedelin H. Relationships between lower urinary tract symptoms, the bother they induce and erectile dysfunction. Scand J Urol Nephrol 2006; 40: 307-12

26 Ushijima S, Ukimura 0, Okihara K, Mizutani Y, Kawauchi A, Miki T. Visual analog scale questionnaire to assess quality of life specific to each symptom of the International Prostate Symptom Score. J Urol 2006; 176: 66571

27 Sarma AV, Wei JT, Jacobson DJ et al. Comparison of lower urinary tract symptom severity and associated bother between community-dwelling black and white men: the Olmsted County Study of Urinary Symptoms and Health Status and the Flint Men's Health Study. Urology 2003; 61: 1086-91

Correspondence: Michael O'Leary, Department of Surgery, Harvard Medical School, Division of Urology, Brigham and Women's Hospital, 45 Francis Street ASB II-3, Boston, MA 02115, USA.

e-mail: moleary1@partners.org

Abbreviations: QoL, quality of life; $A B_{\text {, }}$ $\alpha_{1}$-adrenergic blocker; 5ARI, $5 \alpha$-reductase inhibitor; BO, bother question; BPH-II, BPH Impact Index. 